\title{
A Spatial Analysis of Acupuncture Practitioners in Ontario, Canada: Assessing Regional and Intra-Metropolitan Trends
}

\author{
Stephen P. Meyer \\ Department of Geography / Laurentian University, \\ Canada
}

\section{Introduction}

Regional disparities in health care supply are typically measured in terms of accessibility to family doctors, specialists and other services associated with the conventional medical (CM) sector. Although progress is being made, research on the geographic properties of complementary and alternative medicine (CAM) remains underdeveloped by comparison. CAM's long history of use, continued popularity and commercial success (via chiropractic, massage, acupuncture, homeopathic, naturopathic and other approaches) and slow but insistent integration with CM makes continued study not only logical but necessary. To gain a better understanding of a location's endowment of medical resources, or indeed to compare health care supply amongst areas, it is important to assess both CM and CAM activity. To this end, study needs to evaluate the many diverse sources of medical supply from a geographical perspective.

This paper appends the literature by considering the location properties of acupuncture establishments and does so at two scales: regionally throughout the Canadian province of Ontario and locally within the Greater Toronto metropolitan area. While the emphasis of this study is to describe the spatial patterns of offices listing acupuncture as its main purpose (as classified by standard industrial classification codes), for perspective these primary function acupuncture (PFA) offices are compared to the location tendencies of both CAM collectively (chiropractic, massage, acupuncture, homeopathic, naturopathic and holistic) and 'total' health care supply (CAM plus medical doctor offices, physiotherapists, clinics and hospitals or more generally $\mathrm{CM}$ ). The analysis reveals that acupuncture offices have strong clustering tendencies and that the intra-Toronto concentrations occur in close proximity to Chinese ethnicity enclaves. These spatial outcomes have wider ramifications in terms of: health care policy, the increasingly debated possibility for greater integration between acupuncture, and other CAM approaches, with conventional (Western, biomedical, allopathic) medicine and in understanding the location-specific criteria that are conducive to attracting CAM activity and perhaps in fostering places of healing.

\section{Acupuncture/CAM empirical research: general directions in the literature}

Along with herbology, food therapy, manual treatments and therapeutic exercise (such as $\mathrm{t}^{\prime}$ ai chi), acupuncture is a main discipline of Chinese traditional medicine (Giordano et al., 
2004). Research on acupuncture continues to develop and Li et al. (2010) provide a useful synopsis of the literature. They summarize that the active fields of acupuncture study include: 1) clinical research, such as the safeness of acupuncture, the needle 'placebo' effect, and effectiveness in relieving chronic pain, 2) use of acupuncture (based on client surveys and ethical guidelines of acupuncture experiments) and 3) experimental research on acupuncture mechanisms (that critique and assess acupuncture procedures and the utilization of subsidiary technologies such as functioning magnetic resonance imaging). It is noteworthy that spatial research of any type, whether from the perspective of the patient/client or practitioner, is absent from their summary.

In wider terms, the literature on the geography of health care supply over space is emerging. The body of work is heavily biased towards the conventional medicine sector, with study on the location of, and accessibility to, medical doctor's offices and hospitals being the most common. The geographic properties of complementary and alternative medicine is assessed with far less frequency (in comparison to $\mathrm{CM}$ ), but important contribution do exist (for reviews of the literature, see Andrews et al., 2004; Andrews \& Boon, 2005; Hollenberg \& Bourgeault, 2009; Meyer, 2010). Although quite infrequent, studies that detail the geographic distributions of CAM specialists and/or their clients are available for: chiropractors (Alcantara et al. 2010; Smith \& Carber, 2002; Waalen \& Mior, 2005), naturopaths (Albert, 2009; Albert \& Butar, 2004a, 2004b), chiropractors and naturopaths (Williams, 2000), chiropractors and homeopaths (Brindle \& Goodrick, 2001), homeopaths, paranormal healing and manual therapy (Verheij, 1999) and CAM in general (Andrews, 2003; Meyer, 2008, 2010; Millar, 2001). However, an explicit assessment of the geographic tendencies of acupuncture (a specific type of CAM) has not occurred. This Ontario-wide and Toronto-specific study is believed to be the first to blatantly describe the geography of acupuncture activity and assess the pattern of acupuncture offices over space.

\section{Methodology}

For this analysis, a number of datasets were utilized:

1. The locations and sales estimates of 386, 465 and 431 offices (for the years 2004, 2007 and 2010, respectively) for which acupuncture is the primary medical service;

2. The locations of 4,957 CAM proprietors (for 2007); and

3. The locations of $8,709 \mathrm{CM}$ offices (2007) were added to the CAM total to provide a sample of 'total' health care locations in Ontario.

All of these offices were placed on a street network layer using the 'address locator' geocoding function within the ArcGIS (version 9.3.1) geographic information systems (GIS) software package. With the use of the ArcGIS 'spatial join' feature, these points were agglomerated into Ontario-wide census subdivisions (CSD), which are essentially municipalities, and Toronto-based census tracts (CT) polygons for further analysis. A number of thematic maps and tables were generated to display important geographic patterns. Ethnicity-based 2006 census data were also utilized.

All health care office locations and sales estimates were purchased from InfoCanada (2004, 2007, 2010). The foundation of InfoCanada's databases is phonebooks, but additional records are added with, and the entire collection is verified by, subsidiary sources. While the data-provider estimates an error of up to 10 percent, there is no evidence of systematic bias in the datasets used herein and these samples are believed to accurately reflect the spatial distribution of health care locations in Ontario. Digital base maps (road network files, CSD 
and $\mathrm{CT}$ ) and ethnic origin census variables (Chinese and Southeast Asian) were obtained from Statistics Canada (2006a, 2006b). Figure 1 provides a view of Ontario, the province's four main districts and the largest census subdivisions.

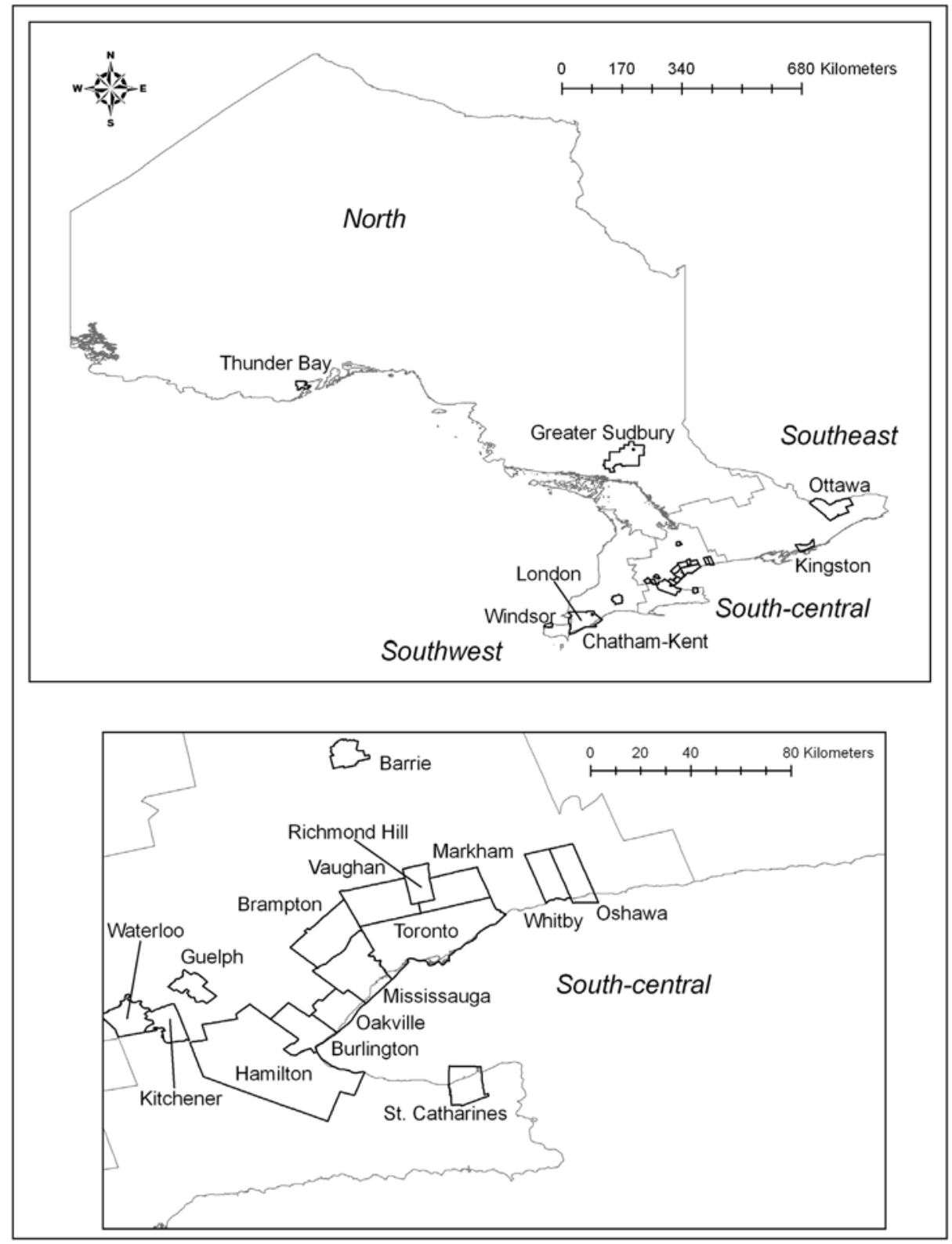

Fig. 1. Census subdivisions in Ontario with a population greater than 100,000 and provincial districts 
To understand relative presence or absence, acupuncture office location quotients were calculated for the census subdivisions throughout Ontario. The following computation was used:

(Number of acupuncture offices in a given CSD / Number of health care offices in a given CSD) / (Number of acupuncture offices in Ontario / Number of health care offices in Ontario)

Location quotient values of 1.2 or greater signify a strong relative concentration or relative specialization (Coffey \& Shearmur, 2002; Meyer, 2007) in primary function acupuncture and values of less than 1 are indicative of relative absence. Location quotients were also derived for census tracts within the Toronto census metropolitan area; calculations were derived for acupuncture offices and ethnic origin (Chinese and Southeast Asian). The following approach was used:

(Number of people of Chinese ethnicity in a given CT / Total number of people by ethnic group in a given CT) / (Number of people of Chinese ethnicity in the Toronto CMA / Number of people by ethnic group in the Toronto CMA)

For the Toronto-specific portion of the analysis, 'significantly clustered acupuncture CSDs' were determined by the Moran's I test for local spatial autocorrelation. Spatial autocorrelation (SAC) can be positive (clustering of phenomena with similar values) or negative (in which neighbouring values are dissimilar) and can be tested for overall global patterns or to determine local hotspots of activity (Boots \& Tiefelsdorf, 2000). In this application, census tracts within the Toronto census metropolitan area (CMA) that test statistically significant (at a confidence interval of 95\%) for local positive spatial autocorrelation comprise clusters of primary function acupuncture offices with comparatively high levels of sales. In other words, this analysis identifies hotspots of acupuncture service activity within the Greater Toronto area. The local spatial autocorrelation analysis was repeated for all CAM offices and for total health care offices (CAM and CM) for comparison purposes.

A temporal dimension was also included in which acupuncture office locations were compared for 2004 and 2010 within metropolitan Toronto. Spatial-temporal trends were evaluated by calculating mean centers and standard deviation ellipses for the distribution of acupuncture office location points. Moreover, temporal change and spatial clustering observations were compared to agglomerations of people with Chinese and/or Southeast Asian origins.

\section{A spatial overview of primary function acupuncture offices in Ontario}

As shown in Table 1, both the acupuncture and more general CAM (chiropractic, massage, holistic, naturopathic, homeopathic and acupuncture) samples show 'urban area' and 'southern province' biases; yet important differences in spatial patterns are apparent. Census subdivisions that are part of census metropolitan areas (populations of 100,000 or more), comprise the largest proportion of both samples: 89.2 and 79.5 for PFA and CAM offices respectively. Yet, CSDs within the Toronto CMA alone contain over half of all acupuncture offices which is far higher than the CAM share (35.7\%) in Canada's largest metropolitan center. CSDs inside smaller metropolitan areas or within census agglomerations (CAs with populations of 50,000 to 100,000) exhibit much higher CAM percentages than PFA (11.0 versus 6.9). While areas outside of CMAs or CAs, show lower proportions, these numbers are consistently far more modest for the specific case of primary 
function acupuncture office activity, in comparison to CAM; and this is true for all categories (strongly, moderately, weakly or not influenced).

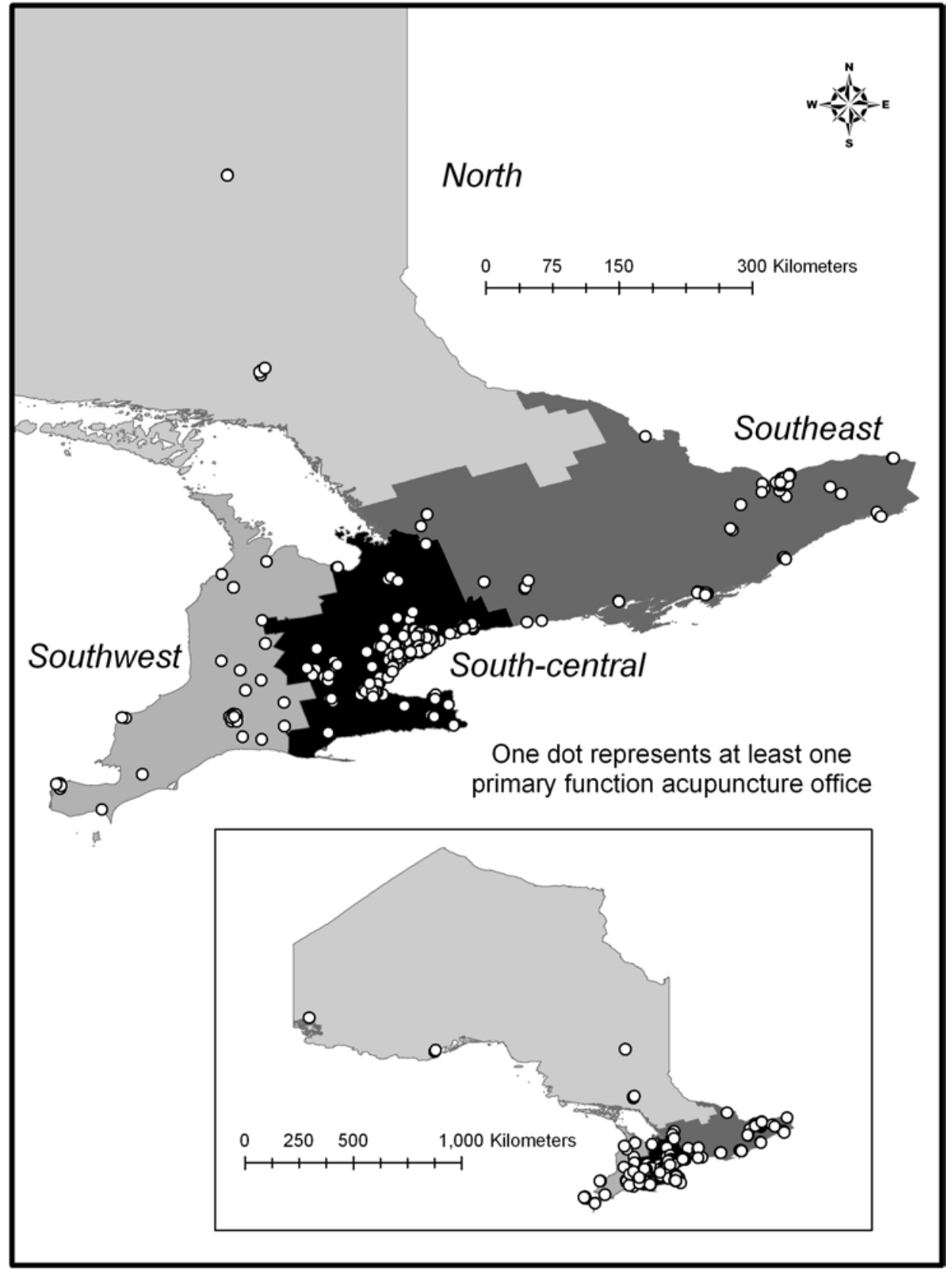

Fig. 2. Location of primary function acupuncture offices in Ontario 
Location propensity differences are also evident by provincial district. The south-central part of the province is the most important in terms of amassing sheer numbers of CAM offices, but the specific case of acupuncture is outstanding with almost three-quarters of the province's PFA establishments in this district (which of course includes the Toronto CMA). The PFA sample has a slightly higher proportion in the southeast. This district contains Ottawa, the province's second largest CMA and the nation's capital city, which houses $6.7 \%$ of Ontario's PFA offices (and 5.0\% of CAM). Conversely, the share of acupuncture office activity, vis-à-vis CAM, is considerably lower in the southwest and northern districts. For specific PFA office locations, see Figure 2.

\begin{tabular}{|l|c|c|c|}
\hline $\begin{array}{l}\text { Census Subdivisions by Statistical } \\
\text { area Classification (SAC) Category }\end{array}$ & $\begin{array}{c}\text { Number of } \\
\text { PFA Offices } \\
\text { and CAM } \\
\text { offices }\end{array}$ & $\begin{array}{c}\text { Percent of } \\
\text { Total : PFA } \\
\text { and CAM } \\
\text { office }\end{array}$ & $\begin{array}{c}\text { Average } \\
\text { Census } \\
\text { Subdivision } \\
\text { PFA Location } \\
\text { Quotient }\end{array}$ \\
\hline SAC & & & \\
\hline Census metropolitan area (CMA): & $249 / 1945$ & $53.5 / 39.3$ & 0.77 \\
\hline \multicolumn{1}{|c|}{ Part of Toronto CMA } & $166 / 1991$ & $35.7 / 40.2$ & 0.31 \\
\hline \multicolumn{1}{|c|}{ Part of other CMAs } & $32 / 544$ & $6.9 / 11.0$ & 0.97 \\
\hline Part of a census agglomeration (CA) & $6 / 147$ & $1.3 / 3.0$ & 0.77 \\
\hline Strongly influenced by CMA or CA & $10 / 181$ & $2.2 / 3.7$ & 0.52 \\
\hline $\begin{array}{l}\text { Moderately influenced by CMA or } \\
\text { CA }\end{array}$ & $2 / 142$ & $0.4 / 2.9$ & 0.06 \\
\hline Weakly influenced by CMA or CA & $0 / 5$ & $0.0 / 0.1$ & 0.00 \\
\hline Not influenced by CMA or CA & & & \\
\hline & & & 0.57 \\
\hline Provincial District & $42 / 729$ & $9.0 / 14.7$ & 0.67 \\
\hline Southwest & $341 / 3255$ & $73.3 / 65.7$ & 0.70 \\
\hline South-central & $69 / 658$ & $14.8 / 13.3$ & 0.07 \\
\hline Southeast & $13 / 313$ & $2.8 / 6.3$ & \\
\hline North & $465 / 4955$ & $100 / 100$ & 0.51 \\
\hline & & & \\
\hline Ontario (total) & & & \\
\hline
\end{tabular}

Table 1. Primary function acupuncture (PFA) and complementary and alternative medicine offices (CAM) in Ontario

The location quotient analysis identifies specific CSDs which are strongly specialized in terms of PFA. Collectively these CSDs display a provincial pattern that provides further evidence that the location choices of acupuncture office practitioners are, in some ways, distinguishable from the more general CAM situation. Meyer (2010) found that CAM specialization in Ontario was wide-spread and prevalent in all four provincial districts and quite evenly distribution across the urban-peripheral continuum (in comparison to conventional medical offices). In contrast, it is very rare for communities to specialize in acupuncture. The last column on Table 1 shows that all of the location quotient averages for the provincial districts or SAC categories are below, and in some cases well below, unity with only the census agglomeration category being close to 1.0. In all, there are only 34 CSDs that scored above 1.20 and achieved 'specialized' status in terms of PFA activity. As shown 
on Figure 3, almost half (15) of these CSDs are located in the south-central (with five in the Toronto CMA alone). Both the southeast and southwest had nine specialized CSDs and it is noteworthy that all but one (Kingston) of these 18 CSDs are located outside of a CMA or CA. The north had only one 'acupuncture specialized' CSD. Although small in number, these municipalities are collectively very important: 294 of the 465 PFA offices in Ontario, or $63.2 \%$, are located in these 34 specialized CSDs.

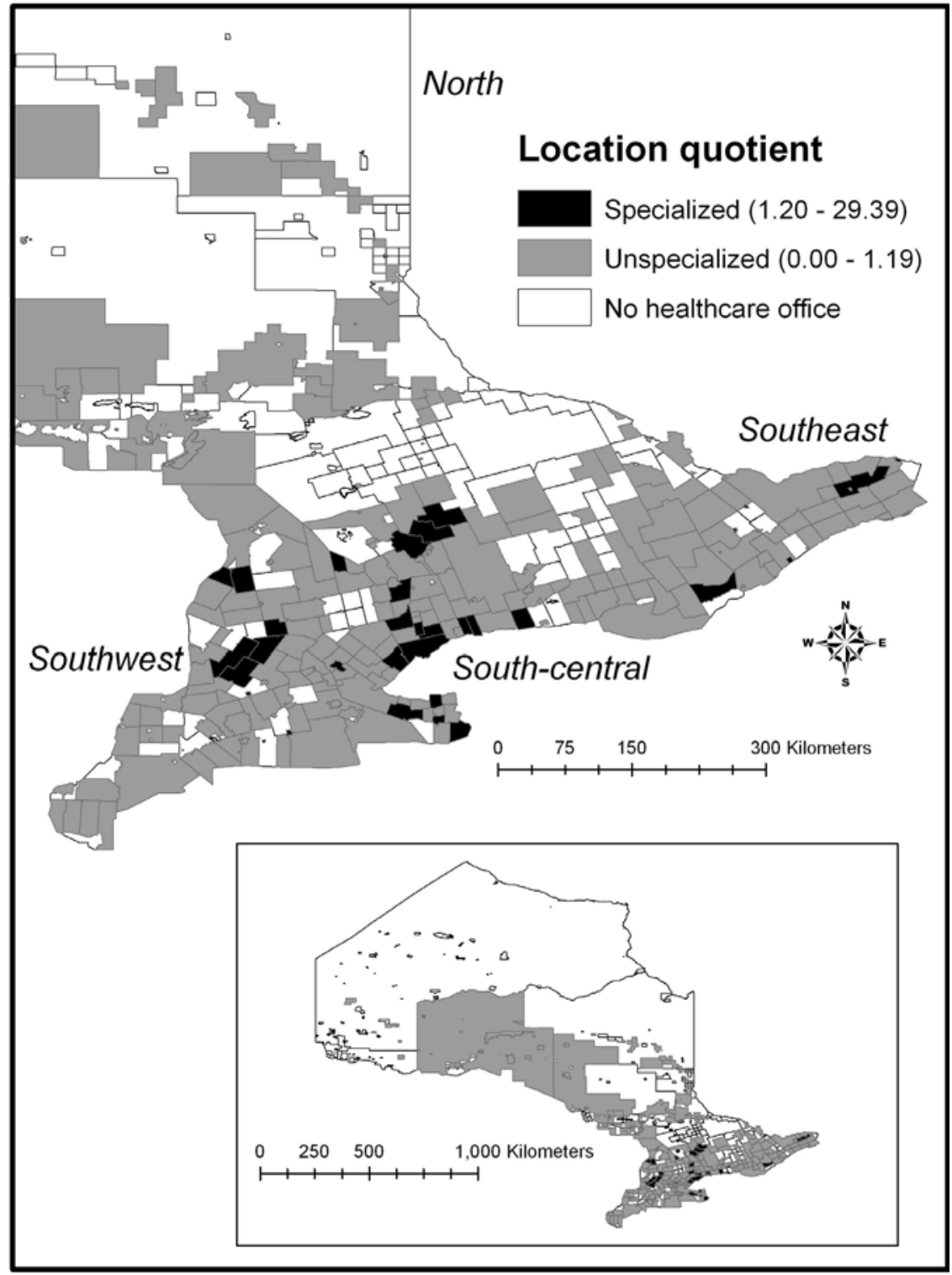

Fig. 3. Primary function acupuncture office by level of census subdivision specialization 
In comparison to other health care providers, the specific subset of PFA features smaller operations with average annual sales of about $\$ 460,000$; which is less than total CAM $(\$ 490,000)$ and much lower than the total health supply $(\$ 830,000)$. This modest size of acupuncture offices remains consistent whether considering the entire PFA sample or the subset of offices in areas of 'acupuncture location quotient specialization'.

Therefore in terms of space, acupuncture office activity shows both commonalities and distinctiveness with the wider complementary and alternative medicine sample. The relatively broad dispersal of CAM in Ontario may be compensating for the lack of CM resources in some less populated and/or underserved areas (Meyer, 2010; Sirois \& PurcStephenson, 2008) and the occurrences of PFA specializations in the southeast and southwest do occur almost exclusively in more peripheral municipalities. On the other hand, PFA office activity is, both in absolute numbers and relative specialization, more polarized and strongly biased to the southern parts of the province and to the Greater Toronto area in particular. With the small size of acupuncture offices and the almost complete abandonment of northern Ontario not withstanding, the extremely strong attraction of PFAs to Toronto might be the most striking contrast between acupuncture and CAM in terms of location choice.

\section{Acupuncture office activity in the Toronto census metropolitan area: clusters, temporal trends and links with ethnic origin}

Since over half of Ontario's PFA establishments (249 of 465 in 2007) are located in the greater Toronto area, this metropolis was designated for detailed analysis. Please refer to Figure 4 to locate metropolitan Toronto's municipalities (CSDs). A local spatial autocorrelation analysis (using Moran's I) was performed in the GIS environment to identify local hotspots of office activity. As shown on Figure 5, there are a number of CTs that were statistically significant for positive local SAC, but arguably four agglomerations stand out. Note the cluster of positive local SAC census tracts in the southern extreme (downtown) of the City of Toronto that radiates northward. As well, there are three other more suburban clusters of acupuncture activity: one that extend from the City of Toronto north into Vaughan, another which bridges Toronto with Markham and a smaller agglomeration in Richmond Hill. These clusters could be dubbed Toronto's 'acupuncture hotspot districts'. Notice that many of these clustered zones are 'partitioned' by census tracts of negative local spatial autocorrelation. Local negative SAC is indicative of abrupt change over space and, in this case, contains CTs with very low PFA sales activity just adjacent to some of Toronto's acupuncture hotspots.

Collectively these localized acupuncture clusters (the positive local SAC agglomerations) represent only 80 of Toronto's 1,003 census tract polygons, but contain an impressive $58.6 \%$ of the CMA's PFA establishments and almost $60 \%$ of sales. These results contrast with CAM and total health care supply (CAM and CM). As also shown on Figure 5, hotspots of total health office activity create a slightly more constricted pattern, compared to the acupuncture office distribution, as these 67 positive local SAC census tracts are located almost exclusively in the City of Toronto. Moreover, these CTs contain roughly 30 percent of the CMA tally in terms of both total number of health care offices and contribution to sales. In contrast, cases of positive local SAC for CAM display a more expansive pattern within the City of Toronto which includes some hotspots in more peripheral communities. Yet, the proportional importance of the CAM establishments in these positive local SAC census tracts echoes the total health care scenario of about 30 percent. 
Thus, primary function acupuncture practitioners create a unique and highly polarized geographic pattern of activity in comparison to other health care providers in general. While the tight spatial clustering of acupuncture activity is not unlike that of total health care (CAM and $\mathrm{CM}$ ), the proportionate size of influence of acupuncture agglomerations is almost double in the hotspots. In addition, the spatial distribution of PFA is very distinct from 'all' types of complementary and alternative medical offices: acupuncture activity is more enclave-like both in geographic distribution and in magnitude of activity (in terms of sales).

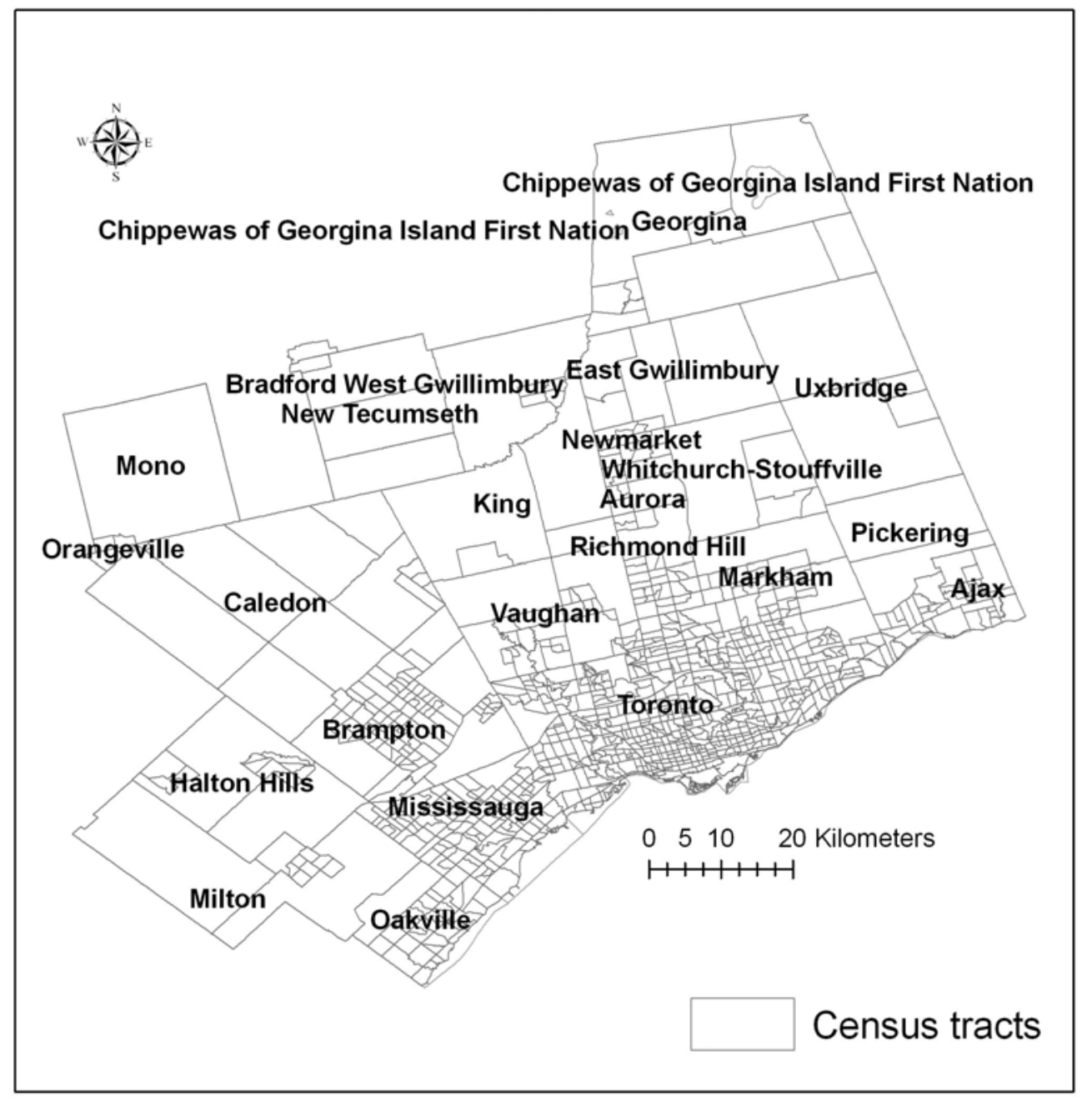

Fig. 4. Municipalities in metropolitan Toronto 


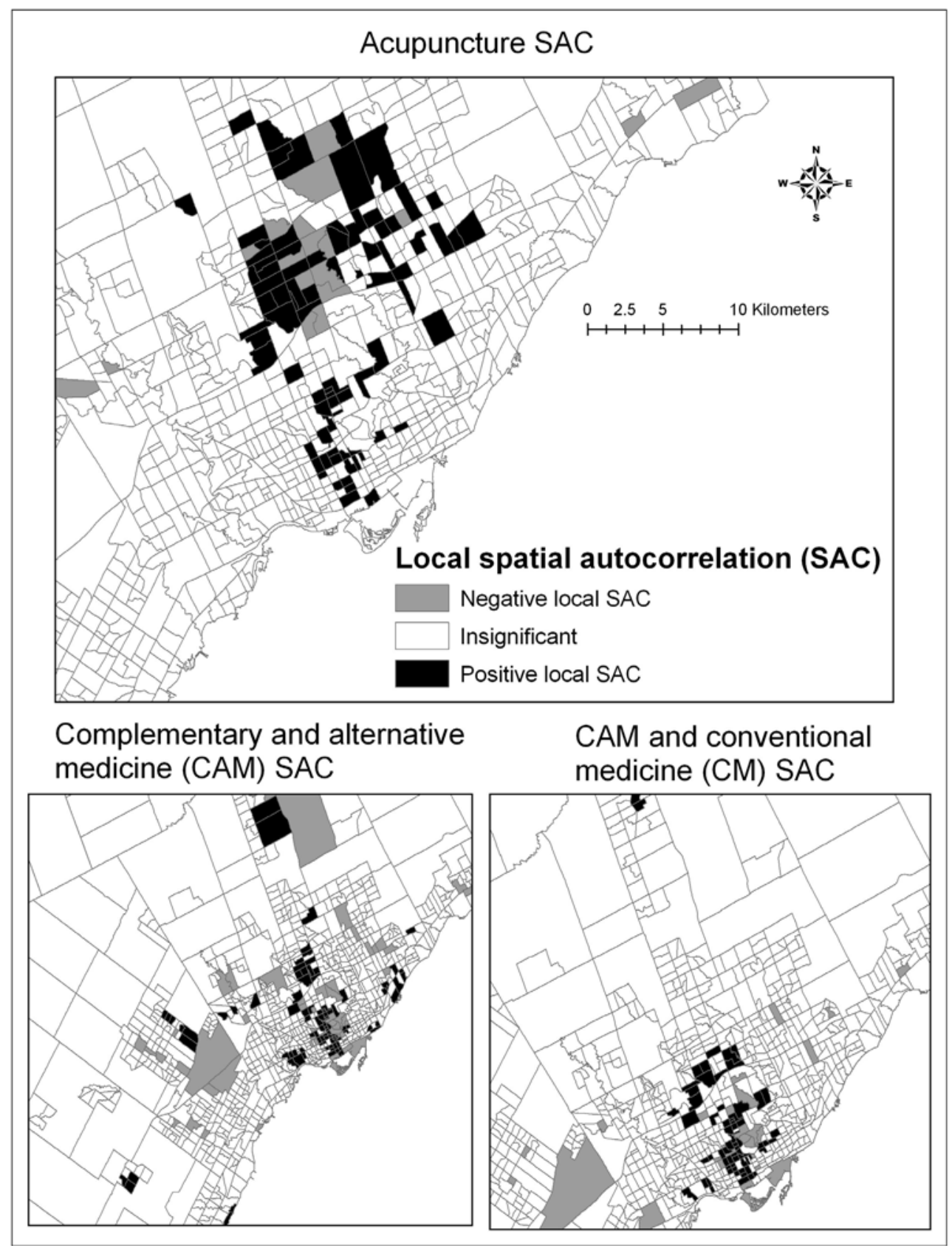

Fig. 5. Statistically significant local spatial autocorrelation census tracts in metropolitan Toronto 
The metropolitan Toronto portion of the paper includes a temporal-spatial analysis of primary function acupuncture activity in which the locations of offices were compared from 2004 to 2010. The overall number of offices did not drastically increasing over this time period (204 to 227). As Figure 6 shows, the vast majority of census tracts either: retained the same number of PFA practitioners, gained one office, lost one office or did not have a PFA office in 2004 or 2010. PFA office loss of two or more did occur in a small number of CTs in the City of Toronto (seven) and one in Richmond Hill. Gains of more than two PFA offices also occurred sporadically in the City of Toronto and in Mississauga. By in large, though, the temporal pattern is quite constant. This stability is further illustrated with the mean centers and standard deviation ellipses. One standard deviation will normally contain $68 \%$ of the features (PFA offices) and two standard deviations will contain 95\%. As Figure 6 shows, there is only a small southwestern shift from 2004 to 2010; that is perhaps indicating modest growth in acupuncture offices in Mississauga. Even with an admittedly short (six year) time frame, it can be said that temporal-spatial shifts are minor and areas in metropolitan Toronto that emphasize PFA tend to be persistent.

Thus, acupuncture activity in the Toronto CMA exhibits clustering tendencies and temporal consistency. This raises another important geographic inquiry: what place-specific criteria are influencing the polarization and persistence of acupuncture establishments? While this is a complex question, there is evidence to suggest a link with PFA and Chinese and Southeast Asian ethnic origins. For census tracts in metropolitan Toronto, location quotients were calculated for both Chinese ethnicity and those of Southeast Asian origins. Yet, given that the Pearson's correlation coefficient of these location quotient values is 0.96 (based on 995 census tracts with ethnic information) and henceforth indicative of almost indistinguishable spatial distributions, only the Chinese ethnic origin results are presented (see Figure 7). Areas of strong relative presence of Chinese populations exist in the City of Toronto's downtown area and in more northern locations of the City of Toronto, Markham and Richmond Hill. These tight clusters correspond with Toronto's 'Chinatown' districts. Visual inspection of Figure 7 with Figure 5 reveals spatial similarities with the acupuncture SAC pattern. Specifically, the acupuncture office clusters indentified by the local spatial autocorrelation analysis appear to correspond closely with neighbourhoods featuring high proportions of Chinese populations.

Table 2 shows the results of more formally assessing this relationship. Chinese ethnic origin location quotients were compared with acupuncture-based positive local SAC and location quotient specialization. Given that the location of acupuncture offices might also be influenced by high Chinese populations in adjacent CTs (and vise versa), buffers were computed around the centroid of local SAC acupuncture CTs and around acupuncture office location CTs with quotients greater than or equal to 1.20. Roughly one-quarter of the 'Chinese' CTs were also classified as acupuncture office hotspots (either by SAC analysis or location quotients). Moreover, over $50 \%$ of the 'Chinese' CTs were no further than 500 meters from key acupuncture areas and almost all were within 2 kilometers. This apparently strong correspondence between acupuncture office activity and Chinese ethnicity population is perhaps not surprising. The techniques inherent to acupuncture have historically been associated with traditional Chinese medicine and it would appear that contemporary spatial patterns of PFA offices remain intrinsically linked with Chinese and/or Southeast Asian enclaves in metropolitan Toronto. 

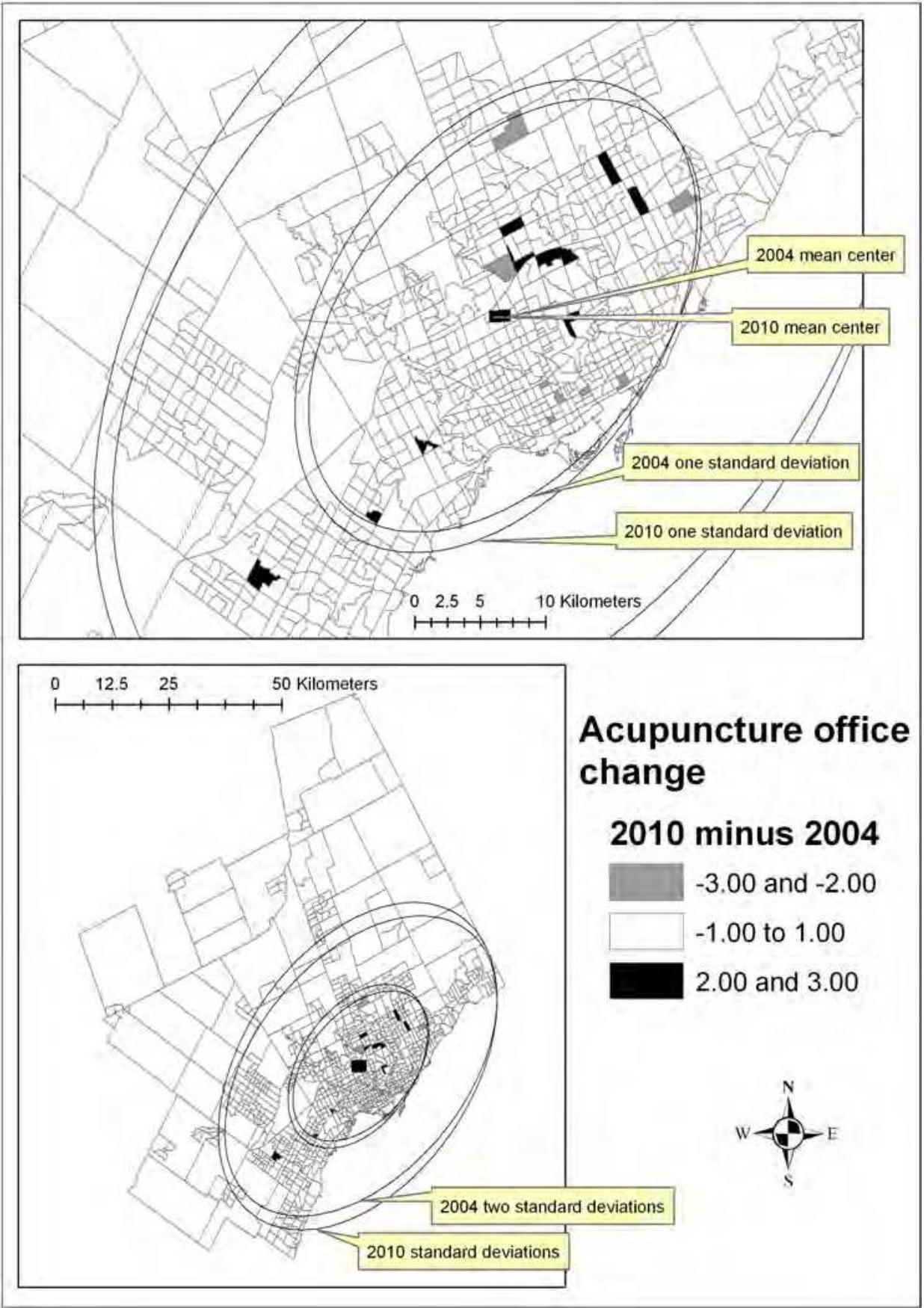

Fig. 6. Temporal changes in primary function acupuncture offices in metropolitan Toronto 


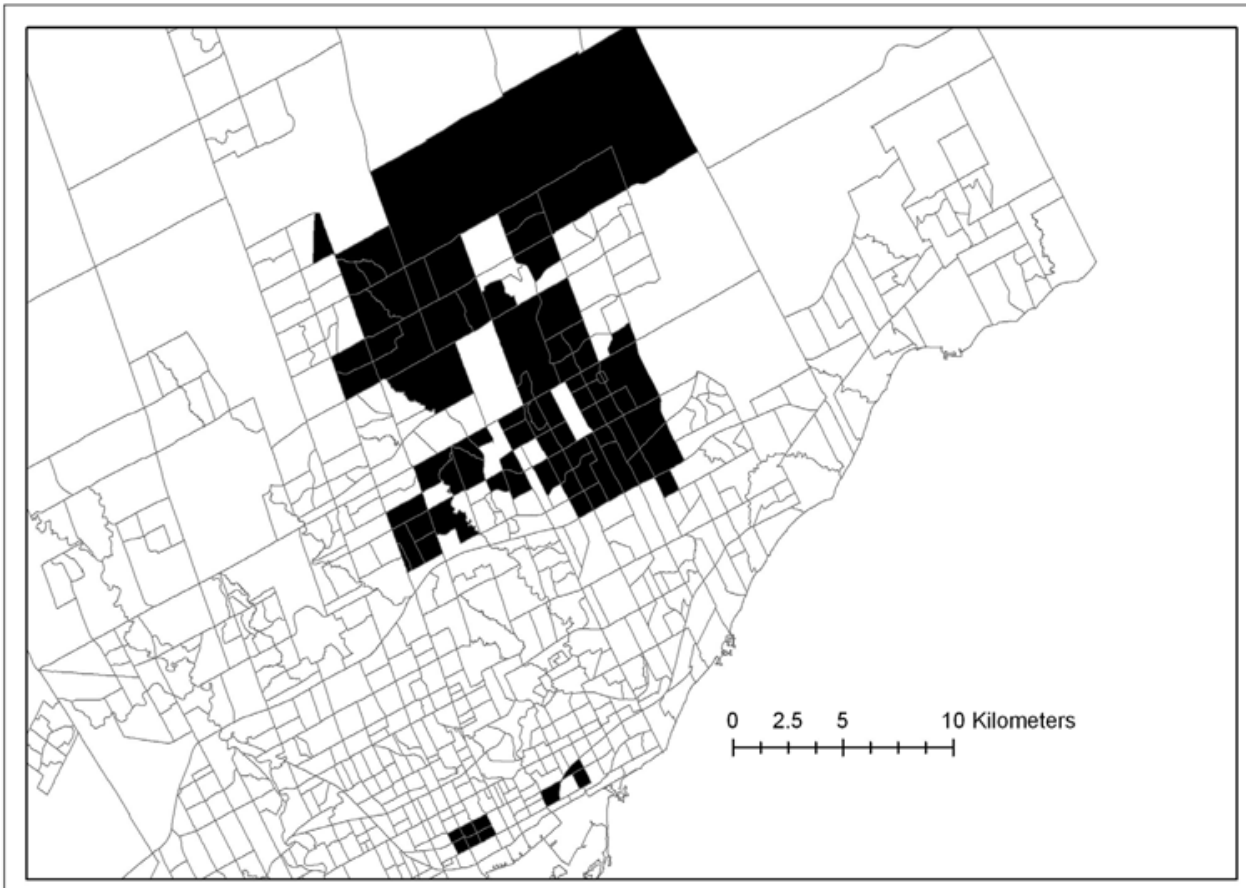

Chinese ethnic origin

\section{Location quotient (LQ)}
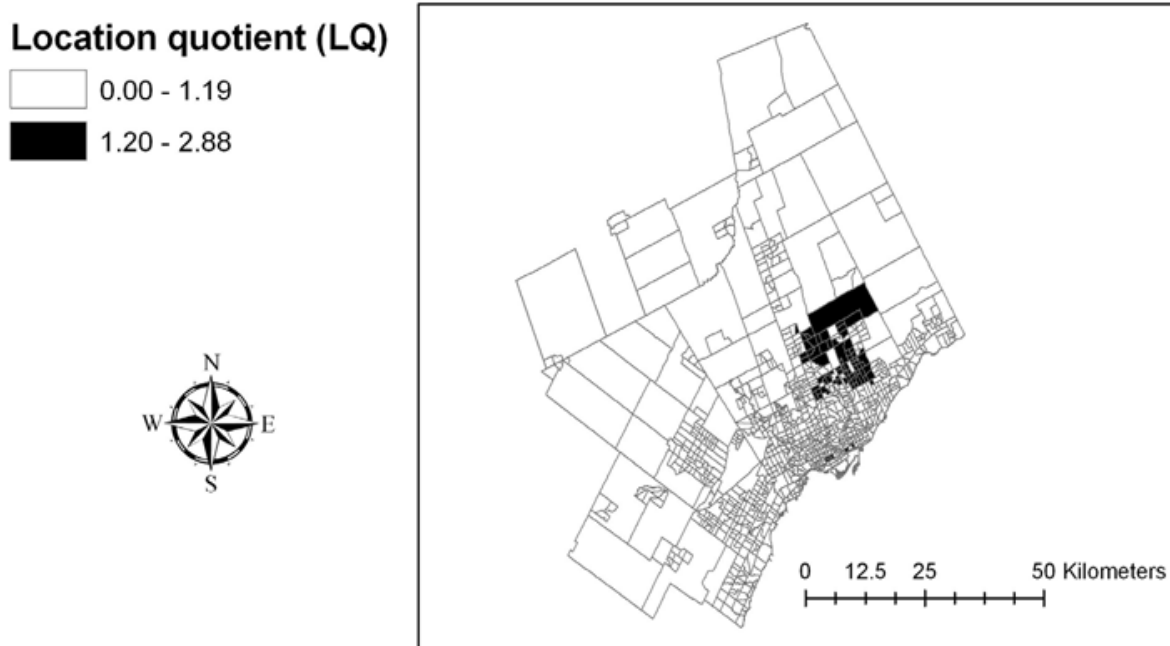

Fig. 7. Chinese ethnicity location quotients in metropolitan Toronto 


\begin{tabular}{|l|c|}
\hline Chinese ethnicity census tracts: & 22 \\
\hline $\begin{array}{l}\text { Intersecting significant local spatial } \\
\text { autocorrelation CTs (based on } \\
\text { acupuncture office sales) }\end{array}$ & 43 \\
\hline $\begin{array}{l}\text { Intersecting significant local spatial } \\
\text { autocorrelation CTs (based on } \\
\text { acupuncture office sales) and within a 0.5 } \\
\text { kilometer buffer of a CT centroid }\end{array}$ & \\
\hline $\begin{array}{l}\text { Intersecting significant local spatial } \\
\text { autocorrelation CTs (based on } \\
\text { acupuncture office sales) and within a 1 } \\
\text { kilometer buffer of a CT centroid }\end{array}$ & 63 \\
\hline $\begin{array}{l}\text { Intersecting significant local spatial } \\
\text { autocorrelation CTs (based on } \\
\text { acupuncture office sales) and within a 2 } \\
\text { kilometer buffer of a CT centroid }\end{array}$ & 78 \\
\hline & \\
\hline $\begin{array}{l}\text { Intersecting specialized acupuncture CTs } \\
\text { with location quotients } \geq 1.20\end{array}$ & 21 \\
\hline $\begin{array}{l}\text { Intersecting specialized acupuncture CTs } \\
\text { with location quotients } \geq 1.20 \text { and within } \\
\text { a 0.5 kilometer buffer of a CT centroid }\end{array}$ & 84 \\
\hline $\begin{array}{l}\text { Intersecting specialized acupuncture CTs } \\
\text { with location quotients } \geq 1.20 \text { and within } \\
\text { a 1 kilometer buffer of a CT centroid }\end{array}$ & 67 \\
\hline $\begin{array}{l}\text { Intersecting specialized acupuncture CTs } \\
\text { with location quotients } \geq 1.20 \text { and within } \\
\text { a 2 kilometer buffer of a CT centroid }\end{array}$ & \\
\hline & \\
\hline Total number of Chinese ethnicity CTs & \\
\hline
\end{tabular}

Table 2. Relating 'Chinese ethnicity' (location quotient $\geq 1.20$ ) census tracts to acupuncture local spatial autocorrelation and acupuncture specialization

\section{Conclusions}

Specialists trained in the discipline of acupuncture not only have the ability to relieve pain and other ailments, but can provide a service that is part of a regimen for maintaining good health. Yet, as with any type of health care service, supply needs to be reasonably proximate to demand. The results from this study illustrate that the spatial distribution of those offering acupuncture treatment is not even and tends to agglomerate in specific portions of the province and indeed within identifiable clusters in metropolitan Toronto. This is certainly true of primary function acupuncture offices. Although given that CAM practitioners in general are more dispersed throughout Ontario and within Toronto, it is likely that some acupuncture services, delivered by chiropractors for example, are fulfilling demand requirements in areas void of PFA offices. Future study could ascertain the extent 
of 'secondary function' acupuncture locations and if these establishments are adequately meeting the demand for acupuncture services. Specifically, research could build on the findings of Bishop et al. (2011), who determined that acupuncturists' trustworthiness and competence are important to potential customers, and establish if these and other patientcentered attitudes towards 'primary' and 'secondary' function acupuncture treatment vary over space.

Giordano et al. (2004) call for discourse regarding the mechanisms for which acupuncture therapies, and more widely Chinese traditional medicine and complementary and alternative health care approaches, could become more integrated into a jurisdiction's public health network. They indicate that much of this responsibility lies with the academic community (doctoral, post-doctoral, facility research and the like) to nurture a 'core of specialists' who would offer advice on how Chinese traditional medicine and other CAM methods could be better incorporated with conventional medicine and in the overall delivery of health care. The authors also state that Chinese traditional medicine is by nature substantially different from allopathic medicine and, thus, this will be a challenge. Tang (2006) goes further and wonders if acupuncture specialists actually should become more integrated with CM and risk becoming 'biomedicalised' and losing its alternative status. Regardless of where one stands on amalgamative possibilities, it is clear that in order to improve the delivery of health care a fundamental understanding of where the demand and supply for these services are located over space is needed. If only conventional medical locations are considered (hospitals and family doctors for example), then a jurisdiction is grossly undercounting resources. A crucial step in health care policy starts with wider recognition for the need to inventory 'total' health care supply. When the dialog from the academic community or policy makers begins to include where CM and CAM resources are located over space and if these resources are where they need to be, then motivation for students to pursue CAM professions becomes increasingly validated, researchers' interests to analyze spatial trends are sharpened and a jurisdiction's stock of health care supply is more accurately portrayed. As such, integrative thinking should go at least to the point of enumerating the various types of CM and CAM in a given place, even if traditional Chinese medicine and other alternative approaches never reach the point of family doctors routinely referring patients for acupuncture treatment, for example.

Given that the quality and quantity of health care resources, funding and overall patient accessibility to medical supply will differ from country to country, province to province and city to city, research on each jurisdiction's inventory of health care supply is desirable; as, admittedly, many aspects will inevitably be case-specific. Yet, this is not to say that universal characteristics are not retrievable. If acupuncture and other CAM stations are clustered in identifiable locations within regions and cities, then research needs to continue to uncover the place-specific criteria driving these distributions. While patient-centered narratives and biographies regarding the use for certain types of CAM (or CAM collectively) are being accumulated by the research community, the nature of places that attract or repel CAM business owners (and overall supply levels) requires much more consideration. This study spatially links high Chinese ethnicity proportions with acupuncture hotspots in Toronto and this particular outcome could also be true in other parts of the world. Even so, this research only begins to uncovering possible explanations for acupuncture office supply concentrations (in Toronto or elsewhere). 
Curtis \& Riva (2010) state that many health geographers are concerned with the healthcentered properties of certain places; an idea often associated with 'therapeutic landscapes'. They also recognize that therapeutic landscapes, or places of healing, might not be experienced the same by everyone. One might hypothesize that the high proportions of acupuncture offices found in close proximity of Chinese ethnicity enclaves (in Toronto or perhaps elsewhere) might be because the acupuncture 'experience' delivered by the offices in these areas coincide with familiar and favorable places of healing for those of Chinese or Southeast Asian backgrounds. Do people of non-Southeast Asian ancestry view these acupuncture hotspots in the same way, or are they just as likely to seek acupuncture services in other areas and/or through a naturopath, chiropractor or registered massage therapist? Williams (2002) claims that it is important for geographers in particular to explore the experiences of patients/individuals as care from formal spaces (such as hospitals and doctor's offices) are shifted to more informal spaces like the home. As such, are acupuncture spaces in Chinese enclaves more secure and 'homelike' as a place of healing? Do the acupuncture specialists themselves, either deliberately or inherently, create a healing environment that appeals to those of Southeast Asian descent in the enclaves? The possible link between acupuncture, ethnicity and places of healing needs to be more completely analyzed.

\section{References}

Albert, D.P. \& Butar, F.B. (2004a). Distribution, Concentration and Health Care Implications of Naturopathic Physicians in the United States. Complementary Health Practice Review, Vol.9, No.2, pp. 103-117, ISSN 1076-1675

Albert, D.P. \& Butar, F.B. (2004b). Diffusion of Naturopathic State Licensing in the United States and Canada. Complementary Health Practice Review, Vol.9, No.3, pp. 193-207, ISSN 1076-1675

Albert, D.P. (2009). New York and Colorado as Critical States in the Diffusion of State Licensing of Naturopathic Physicians. Complementary Health Practice Review, Vol. 14, No. 2, pp. 59-69, ISSN 1533-2101

Alcantara, J., Ohm, J. \& Kunz, D. (2010). The Chiropractic Care of Children. The Journal of Alternative and Complementary Medicine, Vol.16, No.6, pp. 621-626, ISSN 1075-5535

Andrews, G.J. (2003). Placing the Consumption of Private Complementary Medicine: Everyday Geographies of Older Peoples' Use. Health \& Place, Vol.9, No.4, pp. 337349, ISSN 1353-8292

Andrews, G.J., Wiles, J. \& Miller, K.L. (2004). The Geography of Complementary Medicine: Perspectives and Prospects. Complementary Therapies in Nursing \& Midwifery, Vol.10, No. 3,pp. 175-185, ISSN 1353-6117

Andrews, G.J. \& Boon, H. (2005). CAM in Canada: Places, Practices, Research. Complementary Therapies in Clinical Practice, Vol. 11, No. 1, pp. 21-27, ISSN 1744-3881

Boots, B. \& Tiefelsdorf, M. (2000). Global and Local Spatial Autocorrelation in Bounded Regular Tessellations. Journal of Geographic Systems, Vol.2, No.4, pp. 319-348, ISSN 1435-5930

Brindle, M. \& Goodrick, E. (2001). Revisiting Maverick Medical Sects: The Role of Identity in Comparing Homeopaths and Chiropractors. Journal of Social History, Vol. 34, No.3, pp. 569-589, ISSN 1527-1897 
Bishop, F., Massey, Y, Yardley, L. \& Lewith, G. (2011). How Patients Choose Acupuncturists: A Mixed-Methods Project. Journal of Alternative \& Complementary Medicine, Vol.17, No.1, pp.19-25, ISSN 1075-5535

Coffey, W.J. \& Shearmur, R.G. (2002). Agglomeration and Dispersion of High Order Service Employment in the Montreal Metropolitan Region, 1981-96. Urban Studies, Vol. 39, No. 3, pp. 359-378, ISSN 0042-0980

Curtis, S. and Riva, M. (2010). Health Geographies II: Complexity and Health Care Systems and Policy. Progress in Human Geography, Vol.34, No.4, pp. 513-520, ISSN 0309-1325

Giordano, J., Garcia, M.K. \& Strickland, G. (2004). Integrating Chinese Traditional Medicine into a U.S. Public Health Paradigm. The Journal of Alternative and Complementary Medicine, Vol.10, No.4, pp. 706-710, ISSN 1075-5535

Hollenberg, D. \& Bourgeault, I. (2009). New Health Geographies of Complementary, Alternative and Traditional Medicines in Primary Health Care, In: Primary Health Care: People, Practice, Place, V.A. Crooks and G.J. Andrews (eds.), pp. 167-182, Ashgate, ISBN 978-0-7546-7247-0, Surrey, England

InfoCanada (2004). Canadian Business Directory, August 2004 edition, InfoCanada (producer and distributor), Mississauga, $\mathrm{ON}$

InfoCanada (2007). Canadian Business Directory, October 2007 edition, InfoCanada (producer and distributor), Mississauga, $\mathrm{ON}$

InfoCanada (2010). Canadian Business Directory, July 2010 edition, InfoCanada (producer and distributor), Mississauga, $\mathrm{ON}$

Li, H.Y., Cui, L., Cui, M. \& Tong, Y.Y. (2010). Active Research Fields of Acupuncture Research: A Document Co-Citation Clustering Analysis of Acupuncture Literature. Alternative Therapies in Health and Medicine, Vol.16, No.6, pp. 38-45, ISSN 5571-4960

Meyer, S.P. (2007). Finance, Insurance and Real Estate Firms and the Nature of Agglomeration Economies Advantage across Canada and Within Metropolitan Toronto. Canadian Journal of Urban Research, Vol. 16, No. 2, pp. 149-181, ISSN 11883774

Meyer, S.P. (2008). The Spatial Pattern of Complementary and Alternative Medical Offices across Ontario and within Intermediate-Sized Metropolitan Areas. Urban Geography, Vol. 29, No. 7, pp. 662-682, ISSN 0272-3638

Meyer, S.P. (2010). A Geographic Assessment of 'Total' Health Care Supply in Ontario: Complementary and Alternative Medicine and Conventional Medicine. The Canadian Geographer, Vol. 54, No. 1, pp. 104-122, ISSN 1541-0064

Millar, W.J. (2001). Patterns of Use: Alternative Health Care Practitioners. Health Reports, Vol. 13, No.1, pp. 9-21, Statistics Canada, Catalogue 82-003

Sirois, F.M. \& Purc-Stephenson (2008). When One Door Closes, Another Door Opens: Physician Availability and Motivations to Consult Complementary and Alternative Medicine Providers. Complementary Therapies in Clinical Practice, Vol.14, No.4, pp.228-236, ISSN 1744-3881

Smith, M. \& Carber, L. (2002). Chiropractic Health Care in Health Professional Shortage Areas in the United States. American Journal of Public Health, Vol.92, No.12, pp. 20012009, ISSN 0090-0036

Statistics Canada (2006a). Cartographic Boundary, Digital Boundary, Ecumene, Road Network, and Cartographic Attribute Files, 2006 Census of Canada Maps (Machine Readable Data 
Files), Statistics Canada (producer), Ottawa, ON, Statistics Canada Data Liberation Initiative (distributor)

Statistics Canada (2006b). Census of Population, Profile for Census Metropolitan Areas, Tracted Census Agglomerations and Census Tracts (Machine Readable Data File), Statistics Canada (producer), Ottawa, ON, Statistics Canada Data Liberation Initiative (distributor)

Tang, S. (2006). From Outcast to Inboard: The Transmission, Professionalisation and Integration of Acupuncture into British Medical Culture. Asian Medicine, Vol.2, No.2, pp. 254-276, ISSN 1573-420X

Verheij, R.A., de Bakker, D.H. \& Groenewegen, P.P. (1999). Is There a Geography of Alternative Medical Treatment in The Netherlands? Health \& Place, Vol.5, No. 1, pp. 83-97, ISSN 1353-8292

Waalen, J.K. \& Mior, S.A. (2005). Practice Patterns of 692 Ontario Chiropractors (2001-2001). Journal of Canadian Chiropractors Association, Vol.49, No.1, pp. 21-31, ISSN 0008-3194

Williams, A.M. (2000). The Diffusion of Alternative Health Care: A Canadian Case Study of Chiropractic and Naturopathic Practices. The Canadian Geographer, Vol.44, No.2, pp. 152-166, ISSN 1541-0064

Williams, A.M. (2002). Changing Geographies of Care: Employing the Concept of Therapeutic Landscapes as a Framework in Examining Home Space. Social Science E Medicine, Vol.55, No.1, pp. 141-154, ISSN 0277-9536 


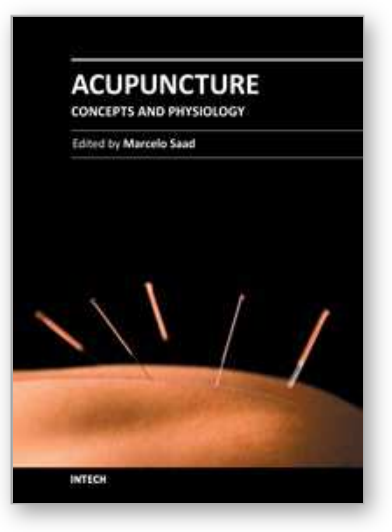

\author{
Acupuncture - Concepts and Physiology \\ Edited by Prof. Marcelo Saad
}

ISBN 978-953-307-410-8

Hard cover, 222 pages

Publisher InTech

Published online 10, October, 2011

Published in print edition October, 2011

Acupuncture and related techniques are useful tools for treating a spectrum of diseases. However, there are still many areas of controversy surrounding it. We hope this book can contribute to guide the advance of this ancient medical art. In the present work, the reader will find texts written by authors from different parts of the world. The chapters cover strategic areas to collaborate with the consolidation of the knowledge in acupuncture. The book doesnâ€ TMt intend to solve all the questions regarding this issue but the main objective is to share elements to make acupuncture more and better understood at health systems worldwide.

\title{
How to reference
}

In order to correctly reference this scholarly work, feel free to copy and paste the following:

Stephen P. Meyer (2011). A Spatial Analysis of Acupuncture Practitioners in Ontario, Canada: Assessing Regional and Intra-Metropolitan Trends, Acupuncture - Concepts and Physiology, Prof. Marcelo Saad (Ed.), ISBN: 978-953-307-410-8, InTech, Available from: http://www.intechopen.com/books/acupuncture-conceptsand-physiology/a-spatial-analysis-of-acupuncture-practitioners-in-ontario-canada-assessing-regional-andintra-metro

\section{INTECH}

open science | open minds

\author{
InTech Europe \\ University Campus STeP Ri \\ Slavka Krautzeka 83/A \\ 51000 Rijeka, Croatia \\ Phone: +385 (51) 770447 \\ Fax: +385 (51) 686166 \\ www.intechopen.com
}

\author{
InTech China \\ Unit 405, Office Block, Hotel Equatorial Shanghai \\ No.65, Yan An Road (West), Shanghai, 200040, China \\ 中国上海市延安西路65号上海国际贵都大饭店办公楼 405 单元 \\ Phone: +86-21-62489820 \\ Fax: +86-21-62489821
}


(C) 2011 The Author(s). Licensee IntechOpen. This is an open access article distributed under the terms of the Creative Commons Attribution 3.0 License, which permits unrestricted use, distribution, and reproduction in any medium, provided the original work is properly cited. 